\title{
Research on the Development and Construction of Scenic Villages under the Background of New Rural Construction
}

\author{
Chuan Sun \\ Hubei University of Education, Wuhan, Hubei 430205, China \\ 25885310@qq.com
}

Keywords: Scenic Villages; New Rural Construction; Sustainable development; Rural tourism

\begin{abstract}
The scenic village is a kind of rural tourism which relies on the villages, takes farmers as the main body, takes the unique natural environment, rural scenery, production and management forms, folk customs and rural settlements as the main attractions, meets the tourists' sightseeing, leisure, vacation, experience, fitness, entertainment, shopping and other purposes. So, we conduct the research on the construction of scenic villages under the background of new rural construction to explore how to carry out effective protection and activation and utilization, and then explore the value of traditional villages to drive the common development of humanity and economy.
\end{abstract}

\section{Introduction}

Under the background of new rural construction, the combination of the protection and development of villages with modern life has become a common concern in academic circles. Discussion on the protection and activation of scenic villages has also become a research type of village development and protection, which has substantial guiding significance for promoting the rapid development of economy, planning, infrastructure and other aspects of villages and the protection planning of natural features. We will improve the pace of local scenic spots development through two major aspects of the design of landscape planning and the design of village planning and construction.

\section{Overview of the construction and planning of traditional villages}

Current situation and development of villages. In recent years, China's economic development and urbanization have accelerated, resulting in the gradual disappearance of a large number of natural villages. According to the survey, the total number of natural villages in China was 3.63 million in 2000, and has dropped to 2.71 million in 2010, which means more than 200 disappeared every day. There are two problems in China's natural villages today, one is empty nest and the other is over-tourism. The protection and development of villages is imminent. The core concept lies in how to correctly handle the relationship between protection and utilization. The protection and development of villages must adhere to the principle of "planning first, overall protection, balance development, rational utilization, government-led, and villagers' main body".

The challenges of village planning. Under the background of urbanization, more and more villagers go to work in large cities for work and employment, resulting in the gradual emergence of empty nest and the lack of labor in villages. Some remote villages are located in mountainous areas and hard-to-develop areas. Geographical restrictions hinder the development of the village and their space can't be expanded.Villages are also faced with the process of "dismantling the old and building new", and the architectural forms are uneven, which has destroyed the original village characteristics. Some villages excessively pursue the economic benefits brought by tourism development and neglect the protection of their culture and history, leading to the over-exploitation of commercialization.In this process, the excessive exploitation and utilization of some scarce and non-renewable resources destroy the natural environment of villages. 


\section{Applicability development measures for scenic villages}

The construction of the village is bound to affect the overall planning of the scenic spot. It is necessary to draw a clear distinction between each other's regions and achieve mutual benefits without affecting each other.As a scenic village its structure pattern is not a simple rural natural mode. The intervention of the scenic spot makes the reconstruction of the village not a single pattern, but also considers the diversity of itself as a part of the scenic spot differentiation with other single village. In terms of nature and humanity, it is more realistic, adhere to principles and flexibility. The reconstruction of the village provides more free space for the villagers and tourists to fully feel the individuality and vitality when they are in the village.

With the rapid development of tourism in China, the improvement of the environment in the scenic spot needs more and more attention. Tourists and villagers gradually increase the pressure on domestic garbage and environmental pollution in scenic spots and villages. Therefore, environmental protection is particularly important. It is necessary to build environmental protection agencies to strengthen inspections and supervision, increase waste treatment facilities in scenic spots and villages, and strengthen village protection, living environment and environmental awareness of the scenic spot, through the local government and scenic spots to jointly maintain the village environment.

In the simultaneous reconstruction of scenic spots and villages, some public spaces should also be retained and rebuilt. Public space is not only a geographical concept, but also a place where people can widely participate, communicate and interact. The villages and scenic spots in the reconstruction must proceed from reality, combine local characteristics and culture, and introduce modern facilities to meet the daily life and needs of the villagers. On the one hand, it will improve the village's water, electricity and road conditions, the construction of public toilets and medical clinics in the scenic spot. On the other hand, it will increase cultural reading, fitness, shopping and other leisure places. Taking into account the integration of traditional public space and modern public space, the villagers' sense of belonging is increased and implemented in the specific planning of villages and scenic spots.

\section{Construction measures of scenic villages}

Optimize the overall layout of the village. The layout of the village is rich and varied, and it is composed of buildings, roads, farmland, plants, water systems, etc. Among them, the dominant buildings form a strict unity of the group, and the layout is flexible and uses the terrain to form a rich layer. The layout of the village is not lost, and the spatial layout is mainly divided into: centralized layout, radial layout, linear layout, and group layout. The layout of the village is relatively random, and the spatial hierarchy is relatively simple. The natural space and the artificial space interpenetrate and interact closely with each other to form an organic whole of the natural environment.

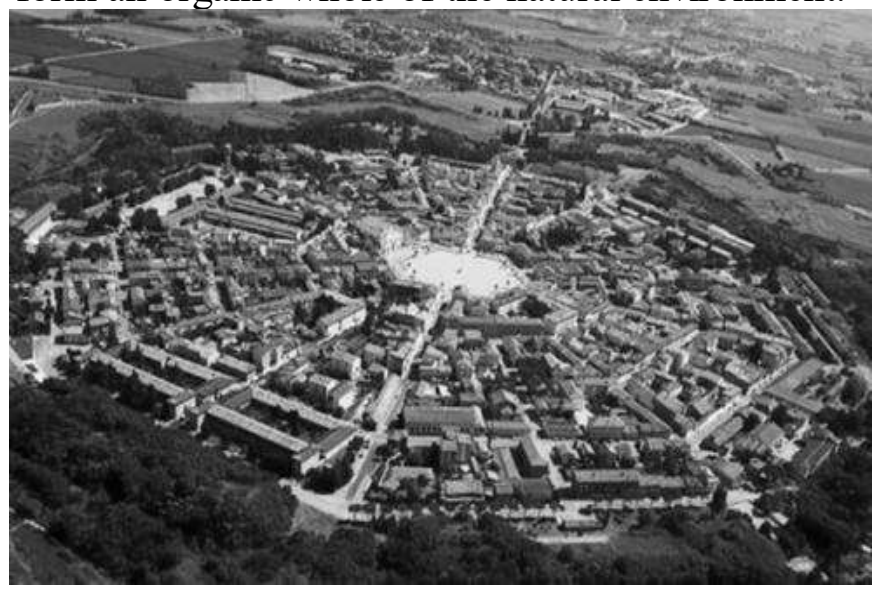

Figure 1. radial layout

Better solving terrain constraints and expanding space. The villages in the scenic spot should have clear boundaries, and the overall planning of the scenic spot and the village space should be carried out. 
The residential function in the village can be relocated to the outside of the scenic spot. The good aspects will make the scenic spot self-recovering in the daily life away from the villagers, making the natural environment in the scenic spot more optimized and more natural. However, blind relocation should be avoided to make the scenic spot lack of cultural landscape to be appreciated, so that tourists can feel the original ecological activities in the village as much as possible. The overall preservation of the village continues the development of humanities. This will not only bring economic growth to bring opportunities to the villagers, but also make the villages more healthy and sustainable development. Some customs and folk customs with local cultural characteristics will be better protected and passed down.

Contradictions caused by industrial development and solutions to the contradictions. With the development of scenic spots, local villagers will gradually transform their industrial forms. The change from farming to commercial will also reduce the production of local cash crops and economic forests. The change from the traditional agricultural production mode to the management mode of vegetable and fruit picking and flower sightseeing in the scenic spot will lose the original characteristics of the village. The village landscape is a limited resource. The transformation of industry and business model invisibly limits the scope of farming and the development space of village facilities. When the original land is protected and the scenic spot is developed, the land use problem is extremely great difficulty. In this context, the production and innovation of agricultural products developed according to local conditions is the only way out. For example, by constructing a centralized production area, planning to focus on the cultivation of local characteristic agricultural products, and focusing on tourism and leisure agriculture as a supporting characteristic agricultural production concentration area to ensure the development of traditional agriculture. At the same time, develop characteristic agriculture such as tourism industry, breeding product processing and rural logistics.

Sustainable development of villages. The sustainable development of village tourism is to meet the various requirements of tourists and villagers while maintaining and developing in the future. The essence of the sustainable development of the village is the coordinated development of economy, society, resources and environmental protection. It is necessary to achieve the development of the economy while protecting the natural resources and environment in which the villagers live in the village, so that future generations can continue to develop and live in peace and contentment. The establishment and development of the scenic spot cannot destroy this kind of harmony. It requires rational use of resources. It is equal to the environment and development, and enhances the participation of the villagers so that they can understand the tourism industry and gain economic benefits, so as to enhance the positive impact and reduce the negative impact.

Strengthening the construction of infrastructure and public facilities. Tourist attractions are spaces or areas where tourism and related activities are the main functions. Tourist roads, parking lots, tourist service centers and toilets are the necessary infrastructure of a scenic spot, which is directly related to the environment and quality of tourists' destination. According to the needs of tourists, we will provide support to improve the tourism environment and continuously improve the quality of tourism products. The supporting facilities of the scenic spots, such as the tourist distribution center, the tourist consultation center, the tourism public sign system, the scenic spot parking lot, and the interior toilets in the scenic spot, need to increase investment to meet the increasing demands of tourists.

\section{Summary}

Rural tourism promotes the simultaneous promotion of human landscapes and natural landscapes in villages. While inheriting traditional local culture and developing villages and civilizations to build a well-off society, it not only enhances the cultural value in the scenic area, deepens and protects the scenic spot appreciation, but also creates conditions for the economic development of villages in the scenic area. The study of scenic villages can provide theoretical support and policy choice for the construction of new socialist countryside and the development of rural tourism. 


\section{References}

[1] Zhou Jian-ming:Chinese Traditional Villages: Protection and Development,Beijing: China's Architectural Industry Press (2014)

[2] Xu Qing:Value reconstruction of new casual and cultural countryside under background of new urbanization,Jiangsu Agricultural Sciences, Vol. 43(2015), No.12:533-537

[3] Hwang D, Stewart W P, Ko D W:Community behavior and sustainable rural tourism development, Journal of Travel Research,Vol.51(2012),No.03 : 328-341

[4] Zheng Wenjun:The Value Cognition and Function Reconstruction of Rural Landscape on Tourism Perspective: Based on the Literatures Analysis, Areal Research and Development,(2013), No.01:102-106

[5] Lin Derong Pan Qian:Study on the Interactive Pattern of Rural Tourism Development and New Countryside Construction, Journal Beijing international studies university,(2009), No.11:67-75

[6] Xu Qing:Functional Reconstruction of Tourism-based Countryside: From the Cask Effect to the Pushpin Effect,Journal of Business Economics,(2016), No.02:89-97

[7] Antrop M: Background Concepts for Integrated Landscape Analysis, (2000), No.77:17-28.

[8] Thomas M F: Landscape Sensitivity in Time and Space:An Introduction,(2000),No.42:83-98.

[9] Feng De-xian, Liang Shao-min:Models of the New Socialist Countryside Construction and Its Dynamics System,Areal Research and Development,(2011), No.06:33-36

[10] Decision by Centre committee of CPC on some important issues regarding promoting country reform development http://www.gov.cn/jrzg/2008-10/19/content-1125094.htm:2011-10-11. 